University of East London Institutional Repository: http://roar.uel.ac.uk

This paper is made available online in accordance with publisher policies. Please scroll down to view the document itself. Please refer to the repository record for this item and our policy information available from the repository home page for further information.

Author(s): Dancey, Christine P.; Friend, Julie

Title: Symptoms, impairment and illness intrusiveness - their relationship with depression in women with CFS/ME.

Year of publication: 2008

Citation: Dancey, C.P.; Friend, J. (2008) 'Symptoms, impairment and illness intrusiveness - their relationship with depression in women with CFS/ME' Psychology \& Health, 23 (8) pp.983-999

Link to published version: $\mathrm{http} / / / \mathrm{dx}$.doi.org/10.1080/08870440701619957

DOI: 10.1080/08870440701619957 


\title{
Symptoms, impairment and illness intrusiveness - their relationship with depression in women with CFS/ME
}

\author{
CHRISTINE. P. DANCEY \& JULIE FRIEND \\ School of Psychology, University of East London, Romford Road, London, E15 4LZ
}

\begin{abstract}
Chronic fatigue syndrome/myalgic encephalomyelitis (CFS/ME) is an illness in which physiological and psychological factors are believed to interact to cause and maintain $\mathrm{CFS} / \mathrm{ME}$ in an individual predisposed to it. The various symptoms and impairments associated with CFS/ME have a large impact on quality of life. The purpose of the present study was to identify the extent to which the core symptoms and impairments associated with CFS/ME relate to depression in women with CFS/ME, and to discover whether these relationships were mediated by illness intrusiveness. CFS/ME was found to be a highly intrusive illness, intruding into more life domains and to a greater degree than other illnesses. The effects of both symptoms and impairment on depression were, in part, mediated by illness intrusiveness. Although symptoms severity and impairment had both direct and indirect effects on depression, illness intrusiveness was the strongest predictor of depression.
\end{abstract}

Keywords: CFS, ME, illness intrusiveness, depression

\section{Introduction}

Chronic fatigue syndrome/myalgic encephalomyelitis (CFS/ME) is a debilitating and often disabling condition which can have devastating effects on the lives of sufferers and their families. It is an illness surrounded by controversy and debate and for which there is still some dispute as to its definition, its diagnosis and its treatment.

Up to $90 \%$ of patients identify a clear onset to their illness (Hotopf \& Wessely, 1994). In such cases, CFS/ME generally follows a severe viral infection (Devanur \& Kerr, 2006). For the minority who have no clear onset to their symptoms, psychiatric illness or psychosocial factors are believed by some to be the underlying problem. However, for the majority of CFS/ME patients, the causes of CFS/ME are now believed to be multifactorial. There is some evidence that genetics may predispose an individual to this illness (Keller et al., 1994). A combination of factors may trigger the illness. A viral infection, combined with lifestyle factors such as taking inadequate rest at the initial stages of the illness and high stress (work stress, emotional or other stresses), may all contribute to CFS/ME. The contribution of stress is believed to be an effect on immune responsiveness (Devanur \& Kerr, 2006). There may be additional factors which maintain the illness, e.g., continuing overactivity, poor sleep, ongoing stresses and lack of social support. Whatever may be the initial causes of this illness, the various symptoms associated with CFS/ME have a huge impact on everyday functioning. As expected, the predominant characteristic is severe fatigue following physical or mental exertion; other characteristics of the illness include muscle pain, sore throat, painful and swollen lymph nodes, unrefreshing sleep, loss of memory and difficulties in concentration (Fukuda et al., 1994). Some people have severe mobility problems whilst others may be principally affected by cognitive or pain difficulties (Shepherd \& Chaudhuri, 2005). At present the use of pharmacological treatments are not universally beneficial (Afari \& Buchwald, 2003), and recent treatment programmes have focused on appropriate rest and pacing, cognitive-behavioural therapy (CBT) and graded exercise therapy (GET), usually in addition to pharmacological treatments.

There have been many studies investigating the efficacy of pharmalogical, psychological and to a lesser extent complementary and alternative therapies for people with CFS/ME. Whiting 
et al. (2001) conducted a systematic review of 36 randomised controlled trials and 8 controlled trials relating to treatments for CFS/ME from 1987 to 2001. The 44 trials included a variety of interventions, outcome measures, and measuring instruments, as well as different types and numbers of people in the trials. This made it difficult to draw overall conclusions from the review. Whiting et al. (2001) stated that there was insufficient evidence of the effectiveness of pharmacological interventions, complementary/alternative therapies and osteopathy for people with CFS/ME. In relation to CBT and GET, eight RCTs were included in the review, and of the three investigating GET, all showed a positive effect compared to the control groups. The number of people rating themselves as better after GET was found to be higher (16/29) in the GET group than the control group (8/30) (Fulcher \& White, 1997) and GET produced improvements in functional work capacity and fatigue (Wearden et al., 1998). Treatment which focused on understanding the physiological basis of symptoms was effective in encouraging GET (Powell, Bentall, Nye, \& Edwards, 2001).

Of the five RCT's investigating CBT, three showed a positive overall effect. CBT was found to be more acceptable and effective than medical care alone in improving patients' day-to-day functioning in the medium (but not the short) term (Sharpe et al., 1996) more effective than guided support in improving fatigue and function impairment (Prins et al., 2001) and more effective when compared to a relaxation control group (Deale, Chalder, Marks, \& Wessely, 1997). The two remaining studies showed no overall effect (Lloyd et al., 1993; Risdale et al., 2001). Shepherd and Chaudhuri (2005) state that CBT may be helpful for a sub-group of patients who have difficulties in coping socially or psychologically, or who have co-existing depression. Research carried out into the impact of CFS/ME on quality of life shows adverse effects on many areas of life, with functional impairment and disruptions to work and social relationships (Rakib et al., 2005). Rakib et al. (2005) found that CFS patients were particularly dissatisfied with their financial matters, likely to be due to a loss of income: $62 \%$ of their sample was unemployed. Hardt et al. (2001) found that quality of life was poor in patients with CFS as compared to the general population and those areas that were most affected were role limitations due to physical problems and lack of vitality. Individuals with CFS/ME have been shown to have substantial levels of disability, even when compared to other chronic illnesses. Schweitzer, Kelly, Foran, Terry and Whiting (1995) found that the degree of impairment was more severe in individuals with CFS than in patients with hyperthyroidism, end-stage renal disease (ESRD) and heart disease. Up to $25 \%$ of individuals with CFS/ME are severely disabled, being confined to bed and unable to perform basic daily tasks such as getting washed and dressed (CFS/ME Working Group, 2002).

With regard to psychological well-being, people with a chronic illness have associated psychological problems, and in medically unexplained disorders in particular there has been some debate as to whether such problems are a consequence of the illness, a cause or contributor to its development. Where psychiatric or psychosocial problems are thought to contribute to CFS/ME, personality traits, anxiety and depression are the most common factors to be investigated. CFS patients have been shown to have higher perfectionism scores than healthy controls (White \& Schweizer, 2000) but not when compared to patients with rheumatoid arthritis (RA) (Wood \& Wesseley, 1999). Childhood trauma has been shown to be a risk factor for CFS (Heim et al., 2006). People with CFS have higher levels of illness worry than an illness control group (Taillefer, Kirmayer, Robbins, \& Lastry, 2003) but not higher levels of general anxiety (Henningsen, Zimmerman, \& Sattel, 2003). Most studies investigating depression in people with CFS/ME show that this illness group has higher levels of depression than other comparison illness groups and healthy controls (Henningsen, Zimmermann, \& Sattel, 2003; Taillefer et al., 2003; Wessely \& Powell, 1989). Taillefer et al. (2003) found that $50-80 \%$ of CFS/ME patients suffer with depression although the depression which manifests in CFS/ME patients may be different from that found in clinically depressed patients (Johnson, DeLuca, \& Natelson, 1996). Henningsen et al. (2003) carried out a metaanalytic review of 244 studies on medically unexplained symptoms. Studies from patients who fell into four groups (IBS, Non-Ulcer Dyspepsia (NUD), Fibromyalgia (FM) \& CFS) were analysed to determine the differences in both anxiety and depression between illness groups and healthy controls. For depression, the CFS studies combined showed the highest difference, with an effect of size $d^{1} 1 / 41.35$. For anxiety, the difference was smaller (d $\left.1 / 40.74\right)$, and lower than that of the NUD group (but higher than the other groups). Studies showing high rates of depression in people with CFS/ME (Wessely \& Powell, 1989) have led some 
people to take the view that depression is a major contributing factor to this illness. Although this is possible, there are several other explanations for this relationship (Afari \& Buchwald, 2003). If depression is posited as a causal factor in such a wide range of illnesses, the mechanisms by which depression is converted into such diverse illnesses have yet to be established. A simple one-way relationship is unlikely however. Iversen and Wessely (2003) state that there is a dual interaction between fatigue and depression, one increasing the risk of the other. It is generally accepted that people with CFS/ME as a group have higher depression levels than other chronic illness groups. Cross-sectional studies cannot of course confirm whether depression is a cause or an effect of CFS/ME; only longitudinal studies can do this. Iversen and Wessely (2003) state that it is fruitless to attempt to work out whether the psychological state came first or after the beginning of the illness. As they say "what is most needed is a pragmatic approach that deals with these problems regardless of their cause" ( $p$. 21).

Living with a chronic illness for which there is no medically explained cause and no effective treatment may itself create anxiety and worry. The perception that others were not taking their illness seriously was found to account for part of the higher illness worry scores (Taillefer et al., 2003) and also the higher depression and anxiety scores (White, Lehman, Hemphill, Madel, \& Lehman, 2006) found in people with CFS/ME. These latter researchers, using metaanalysis, found that people with a chronic illness where the cause was uncertain had raised anxiety and depression compared to those where the cause was known. Lehman, Lehman, Hemphill, Mandel and Cooper (2002) found that people with CFS who believed that their physician did not legitimize their illness had higher depression and anxiety scores than people who did not hold this belief.

Looper and Kirmayer (2004) state that patients with functional syndromes such as CFS/ME often feel that their experience of being physically ill is not validated, and state that the higher levels of stigma in this group is likely to be the ambiguity regarding the cause of the condition. Perceived stigma is, unsurprisingly, related to measures such as depression and quality of life (Dancey, Hutton-Young, Moye, \& Devins, 2002; Looper \& Kirmayer, 2004). Although physical symptoms themselves may contribute directly to reduced well-being, research from a wide variety of both acute and chronic illnesses show that much of the degradation in quality of life comes from the intrusiveness of an illness (Devins, 1994). Illness intrusiveness is the extent to which the symptoms and treatment of a chronic, disabling or life-threatening illness impacts on an individual's life and intrudes on valued aspects of his or her lifestyle, activities and interests, leading to reduced feelings of psychological well-being (Devins et al., 1996). Devins (1994) states that illness intrusiveness compromises psychosocial well-being in two ways: (1) by reducing the availability of experiences which positively reinforce well-being (2) by reducing perceived control over important life outcomes. For example, fatigue associated with certain chronic illnesses can lead to an individual having to give up work, which in turn can lead to financial difficulties, thus adversely affecting overall quality of life and psychological well-being. There are many different areas of an individual's life which may be affected by illness - such as career, recreation and relationships. For example, people who suffer from IBS find that their illness intrudes principally in the domains of diet and health (Dancey et al., 2002). In the case of RA (Devins, Edworthy, Guthrie, \& Martin, 1992) the domains in which the illness is most intrusive (apart from diet and health) are work and finances, domains which are not highly intrusive in those with IBS. Studies across many different illnesses such as ESRD, RA, Cancer, Lupus (Devins et al., 2001), Diabetes (Talbot, Nouwen, Gingras, Belanger, \& Audet, 1999) and MS (Shawaryn, Schiaffino, Larocca, \& Johnston, 2002) have shown that features of the chronic illness affect depression through illness intrusiveness and that these are an underlying determinant of the psychosocial impact of an illness (Dancey et al., 2002; Devins et al., 2001). Variables which moderate the effect of illness intrusiveness on depression and/or quality of life have been identified in many illnesses, e.g., age and gender (Devins et al., 1996), perceived stigma (Dancey et al., 2002; Devins, 1994) and stressful life events (Devins et al., 2006). Once moderator variables have been identified in a specific illness, it is possible to design intervention programmes which reduce their impact and improve well-being. For example, a brief supportive-expressive psychotherapy group helped people with systemic lupus erythematosus (SLE) to adapt to their illness by enabling them to reduce the intrusiveness of the illness into significant life domains (Edworthy et al., 2003). 
At present, there appears to be a lack of research available on illness intrusiveness with respect to CFS/ME. Given the nature of CFS/ME, however, it would be expected that illness intrusiveness would be high. In any investigation there are a number of potential variables that could be studied. The strongest and most consistent psychological difference between people with CFS/ME and other illnesses has been depression, and it is for this reason that we decided to focus on this variable. Based on work in other chronic illnesses (Devins et al., 1993a) it would be reasonable to expect that at least some of the depression felt by people with $\mathrm{CFS} / \mathrm{ME}$ would be due to the intrusivity of the illness.

The main aim of the study is to assess the relationship between CFS/ME (symptoms and impairment) and depression, and to explore illness intrusiveness as an intervening variable. Based on the literature presented above, we predict that, as in other illnesses, the relationship between symptom severity (and impairment) to depression will be mediated by illness intrusiveness. In addition, this study will clarify the nature of the intrusivity of the illness, and will identify which life domains are the most depressing. It is expected that results will substantiate the illness intrusiveness framework and support its relevance for people with CFS/ME. The results from this study may inform efforts to design effective intervention programmes which focus on reducing the intrusiveness of CFS/ME.

\section{Method}

\section{$\underline{\text { Participants }}$}

140 women (mean age $1 / 447.76, S^{1 / 411.55)}$ with CFS/ME participated in the study. All had replied to requests for research volunteers placed in the publications of two British CFS/ME charities. Mean duration of illness was 11 years 4 months (SD $1 / 49$ years 1 month).

\section{$\underline{\text { Design }}$}

The study was a naturalistic correlational design, which examined the relationships between the following variables: symptoms, impairment, illness intrusiveness and depression.

\section{Materials}

\section{$\underline{\text { Severity of symptoms questionnaire }}$}

The symptoms were based on criteria by Fukuda et al. (1994) and were fatigue, memory/concentration problems, sore throat, swollen glands, general pain, joint stiffness/pain, headaches and unrefreshing/disturbed sleep. These symptoms were rated on a Likert-type scale where 1 is not at all severe and 7 is extremely severe. Ratings were added to give a total symptom severity score.

\section{Impairment questionnaire}

The disabling effects of the illness and the extent of impairment were measured using a 12 item questionnaire, based on Cox and Findley's (1998) four categories of severity in CFS/ME. The first 3 questions relate to the Mild category, where patients are mobile, self-caring and able to carry out light domestic tasks with relative ease. Questions 4-6 relate to the Moderate category, where patients have reduced mobility, have had to stop working and need many rests throughout the day. Questions 7-9 relate to the Severe category where they may be wheelchair dependent, have cognitive difficulties and are generally house-bound. Questions 10-12 relate to the Very severe category where patients are unable to mobilise or carry out any daily task and are bedridden for most of the time. The 12 questions involved a yes or no answer. As most participants did not fall easily into one particular category, the following scoring system was used. Where participants showed impairment relating to any of the items, their score was "1". The scores for each category were summed separately. For the 
moderate category, the total was weighted $\left({ }^{*} 2\right)$; for the severe category $\left({ }^{*} 3\right)$ and for the very severe ( $\left.{ }^{*} 4\right)$. The sum of these categories gave a "total impairment" score.

\section{$\underline{\text { Illness intrusiveness ratings scale }}$}

Illness intrusiveness was assessed using the Illness Intrusiveness Ratings Scale (Devins et al., 1994). This measures the extent to which an illness intrudes in 13 life domains: health, diet, work, active recreation, passive recreation, relationship with spouse, sex life, finances, family relations, other social relations. Participants were asked to rate the extent to which their illness interferes with each of the 13 domains, using a seven point Likert type scale, where 1 is "not very much" and 7 is "very much". CES-D scale. Depression was measured using the 20-item CES-D scale (Radloff, 1977). Participants were asked to rate the 20 items on a scale of $0-3$, where 0 is "rarely/none of the time" and 3 is "most or all of the time". The scoring was to reflect how the participants had felt during the past week. According to population norms, $<161 / 4$ no depression; 16-211/4mild to moderate depression and $1 / 4>22$ is probable major depression (Radloff, 1991).

\section{Procedure}

\section{Ethics}

Before beginning the study, ethical clearance was obtained and throughout the study ethical principles were maintained regarding confidentiality, withdrawal from the study and informed consent. A request for participants was inserted into the magazines of two CFS/ME organisations. People who wished to participate were asked to write to us, whereupon they received information relating to the study (including inclusion and exclusion criteria), questionnaires, and a consent form. A top sheet asked participants to confirm sex, age, whether CFS/ME had been diagnosed by a qualified medical practitioner, duration of CFS/ME and any other co-existing illnesses. As this sample was obtained via charities representing the interests of people with CFS/ME, and questionnaires were sent and received by mail, no further diagnostic procedures were employed. The questionnaires were packed in various different orders, and participants were asked to complete them in the order given. A prepaid envelope was included in the pack for the return of the completed questionnaires. Participants were informed that a summary of the findings of the study would be provided through the two charities' respective publications. Participants were also given contact details of the researcher in case they had any questions or queries about the research. A total of 176 women contacted us for information. A total of 141 questionnaire packs were returned to us (an $80 \%$ response rate from those who expressed an interest in the research) although one of these had too much missing data to be included.

\section{Results}

\section{Duration of illness}

The duration of CFS/ME was not associated with symptom severity, impairment, illness intrusiveness or depression ( $\mathrm{r}^{1} / 40.01,0.04,0.026$ and $\_0.002$ respectively; all n.s.)

\section{Symptom severity}

The possible range of scores was between 8 and 56 . The mean total symptom score was 39.1 (SD $1 / 48.81$ ); the scores ranged from 18 to 56 . Means and standard deviations for individual symptoms are seen below (scored ranged from 1 to 7 ). Fatigue, unsurprisingly, was rated as the most severe symptom (Table I).

\section{Severity of impairment}

The following table gives the percentage of people who were impaired in the four categories of the impairment questionnaire (Table II). Adding the scores according to the weighted- 
system gave a mean total impairment score of 14.93 (SD1/46.03). The possible range for these scores was $0-30$.

$\underline{\text { Illness intrusiveness }}$

The mean total illness intrusiveness score was 65.84 (SD1/413.91). The possible range for scores was 7-91. This figure is much higher than other comparison illnesses, as can be seen in the Figure 1. The intrusiveness of the illness naturally varied across the domains, as can be seen in the Figure 2.

$\underline{\text { Table I. Descriptive statistics for eight core symptoms of CFS/ME. }}$

\begin{tabular}{lll} 
Symptom & Mean & SD \\
\hline Fatigue & 6.52 & 0.87 \\
Sleep difficulties & 5.50 & 1.28 \\
Memory/concentration & 5.23 & 1.63 \\
Joints/muscles & 5.23 & 1.67 \\
Pain & 5.00 & 1.97 \\
Headaches & 4.41 & 2.23 \\
Swollen glands & 3.75 & 2.01 \\
Sore throat & 3.42 & 1.99
\end{tabular}

Table II. Impairment: Percentage of sample who showed impairment in 12 specific domains.

Symptom
category Item Yes No

Mild

Moderate

Severe

Very severe
Are you mobile

Carry out light tasks

Care for yourself

Mobility reduced

Give up work

Require rests

In a wheelchair

Memory problems

Rarely leave home

Bedridden

Unable to carry on with tasks

Sensitive to light and noise
89.3

87.1

84.3

92.1

85.0

92.9

18.6

90.7

45.7

12.1

34.3

65.7
10.1

12.9

15.7

7.9

15.0

7.1

81.4

9.3

54.3

87.9

65.7

34.3 


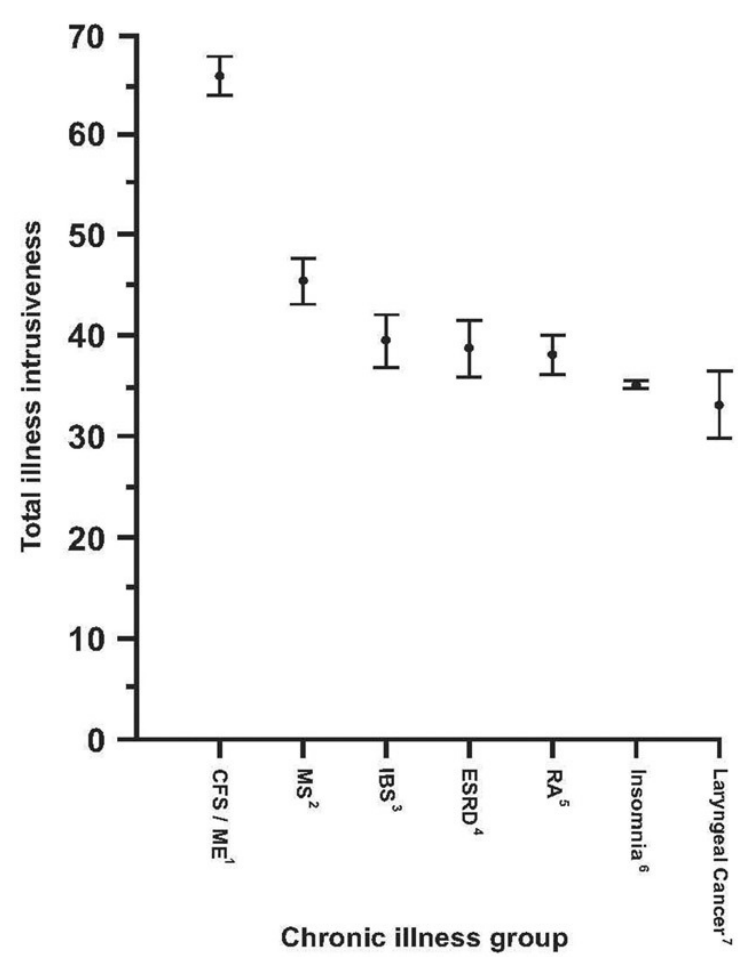

Figure 1. Means and confidence intervals (95\%) for illness intrusiveness in different illness groups. 1. Present study 2. Devins et al. (1996) 3. Dancey et al. (2002) 4. Devins et al. (1990) 5. Devins et al. (1993b); 6. Devins et al. (1995) 7. Devins, Stam and Koopmans (1994).

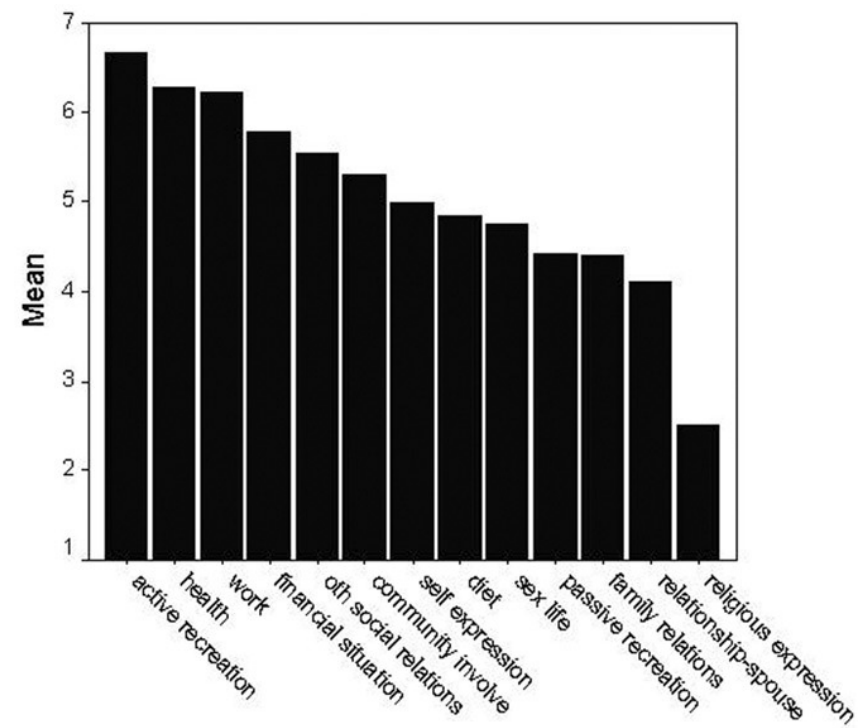

Figure 2. Mean illness intrusiveness across domains. CFS/ME is most intrusive in the domains of active recreation, health and work.

The relationship of illness intrusiveness and symptom severity to depression

The mean depression score was 23.1 (SD1/412.30). For this sample, $31.4 \%$ fell into the "not depressed" category, $20.7 \%$ into the "mild to moderate" and $47.9 \%$ into the "probable major depression" category. The percentage of women with CFS/ME who fall into the "depressed category" (16 or above, see Radloff, 1991), at $68.6 \%$ is higher than that reported for other illnesses. As expected, illness intrusiveness relates to depression $(0.31, p<0.001)$. However, the intrusion of CFS/ME into some life domains vary according to how depressing they are. The intrusiveness of CFS/ME was most depressing in the area of the relationship with spouse or partner $(0.33, p<0.001)$, self expression $(0.30, p<0.001)$ and diet $(0.26, p<0.001)$. 
Pearson's correlation coefficients were calculated to test the hypotheses that illness intrusiveness mediates the relation between impairment (and severity of symptoms) and depression. This requires that statistically significant correlations exist for impairment (symptom severity) and illness intrusiveness and between impairment (symptom severity) with depression. The correlation between impairment (symptom severity) and depression must be lower after statistically controlling for illness intrusiveness (Baron \& Kenny, 1986). Results satisfied these criteria.

The relation between impairment and depression was $r^{1 / 40.21} ; p^{1 / 40.008}$; this reduced to $r^{1 / 40.11}\left(p^{1 / 40.09}\right)$ when illness intrusiveness was partialled out. The relationship between symptom severity and depression was $r^{1 / 40.20} ; p^{1 / 40.008}$; this was reduced to $r^{1 / 40.13}$ $\left(p^{1 / 40.07)}\right.$ when illness intrusiveness was partialled out. This demonstrates that illness intrusiveness is a (partial) mediator between impairment (symptom severity) and depression.

Further information can be gained by looking at all the variables in the hypothesised model, by constructing a path diagram. Beta weights are then calculated for each hypothesised path. The causal structure is the one hypothesised by us. Although path analysis cannot validate the causal structure, the path coefficients are partial, standardised $b$ weights and therefore can be compared directly with each other. The beta weights were calculated by performing two standard multiple regression analyses within SPSS, (a) using depression as the criterion variable and (b) using illness intrusiveness as the criterion variable. Both regression analysis were statistically significant $\left(R^{1} 1 / 40.342\right.$ and $R^{1} 1 / 40.274$, respectively, $\left.p<0.001\right)$ (Figure 3 ).

These are weak effects, demonstrating that although impairment, symptom severity and illness intrusiveness contribute to depression, other variables need to be identified and included in the model.

\section{Discussion}

The present study clarifies the way in which symptoms and impairment affect depression in women with CFS/ME. The symptoms, and especially the impairments and disabilities experienced by people with CFS/ME (e.g., mobility problems, memory problems) intrude into aspects of life which narrows the world of women with CFS/ME. The illness is extremely intrusive. In fact CFS/ME was found to be more intrusive than other chronic illnesses such as IBS, laryngeal cancer and ESRD, even though cancer and ESRD are considered more

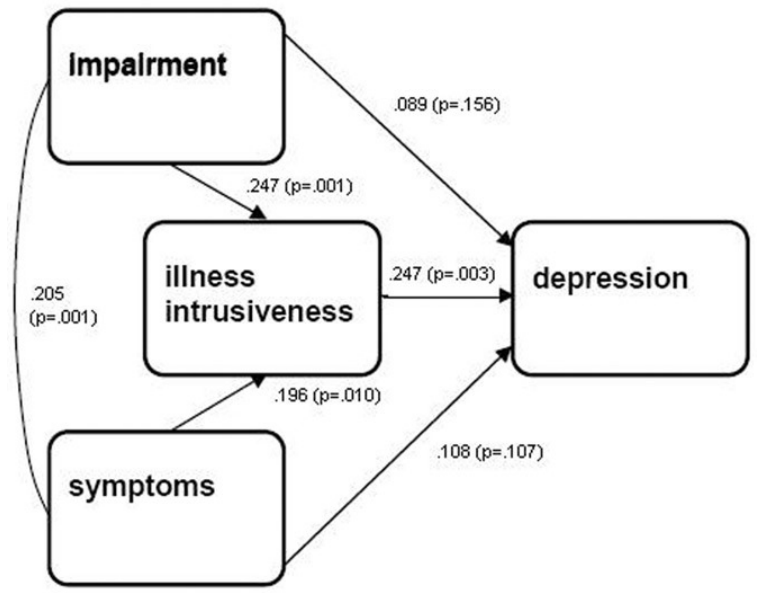

Figure 3. Path diagram.

serious illnesses due to their life-threatening nature, confirming findings by Schweitzer et al. (1995). Similarly, Buchwald, Pearlman, Umali, Schmailing and Katon (1996) found that in comparison to chronically ill medical populations, individuals with CFS/ME are "strikingly disabled" (p. 369). Our study shows that CFS/ME intrudes into more life domains, and to a greater degree, than the other illnesses with which it is compared. CFS/ME intrudes into health, active recreation and work more than other aspects of life. However, this does not mean that these intrusions are the most depressing. In fact, CFS/ME intrudes less into 
"relationship with spouse" than other aspects, but it is the intrusion into this domain of life which contributes most to depression. This study did not seek to clarify the possible reasons why this might be so, and is a topic worthy of further research.

Astonishingly, the great majority of the participants in the current study have had to give up work. This is usually not the case with other chronic illnesses, such as IBS for example, where the life domain of work is hardly affected (Dancey et al., 2002). Even patients with MS tend not to be so affected: in a study by Johnson et al. (1996) $89 \%$ of patients with MS were working full time, whereas only $44 \%$ of the CFS/ME patients were able to work. The percentage of participants giving up work in this sample is unusually high in this study, when compared with other studies (Johnson et al., 1996; Rakib et al., 2005). This may be a reflection of this particular sample; it may be that people with CFS/ME who are more severely affected are more likely to respond to requests to take part in research studies which do not involve travel. Clearly, giving up work tends to mean a reduction in income and individuals may have to rely on family/friends for financial support. This in turn can lead to a loss of selfesteem and to feeling that life has little meaning (Delongis, Folkman, \& Lazarus, 1988).

With a loss of work/career often comes a loss of social relations. The workplace is for many a source of friends and a place of belonging. For many people work/career defines who they are and therefore having to give up one's job can lead to a loss of identity and self-worth. In their study of functional status in patients with CFS/ME, Buchwald et al. (1996) found that on average CFS/ME patients scored low on social functioning, an area which, for other seriously ill medical patients, seems relatively preserved. Individuals with CFS/ME often find it extremely difficult to keep up with social activities due to their fatigue and this can lead to social isolation and the loss of roles which were previously valued (Schweitzer et al., 1995). This of course is the mechanism by which illness intrusiveness exerts its effects (Devins, 1994).

With regards to hobbies and recreational life, there is a marked reduction of these activities in people with CFS/ME due to fears of possible exacerbation of symptoms or to the fact that individuals have too little energy to engage in these activities in the first place, especially activities which require a certain amount of physical exertion. Hence, the high intrusiveness of CFS/ME into the "active recreation" domain.

Compared to other illnesses, a higher proportion of women with CFS/ME show elevated levels of depression. Clearly there could be several or many contributory factors to depression, as was discussed earlier. However, our study shows that a high level of intrusivity into valued interests and activities is an important factor, confirming studies of other chronic illness groups which demonstrate illness intrusiveness as a mediator between symptoms and depression (e.g., Shawaryn et al., 2002). According to findings by Johnson et al. (1996) depression is not closely related to disability in CFS/ME patients.

Our study has shown, in keeping with Devins (1994) theory that such a finding is likely to be because the direct effects of disability on depression are slight. It is the effects of illness intrusiveness rather than a direct effect of the disability on psychological state which is important. The experience of symptoms such as fatigue, memory and concentration problems, headaches etc. seem also not to be a simple psychological effect. These symptoms mean that people with CFS/ME reduce or give up important activities and hobbies which are an important part of quality of life. The combination of experienced symptoms and disabilities mean that individuals with CFS/ME may be unable to enjoy leisure and social activities which they may have previously participated in, or that they may be unable to work or pursue their chosen career. This reduction of the availability of experiences which positively reinforce well-being compromises psychosocial well-being (Devins, 1994).

\section{Limitations of the study}

Before concluding, it is important to acknowledge the limitations of this study. The crosssectional, correlational nature of our experimental design cannot establish causal directionality among the variables highlighted in this study. It was not possible in this study to 
obtain independent verification of diagnosis. However, the present sample had symptoms which were consistent with CFS/ME and had joined a self-help organisation for people with this illness. They stated that they had been diagnosed by a qualified medical practioner as having CFS/ME. It is not unreasonable to assume that the sample did in fact have CFS/ME.

It is not possible to know whether our sample is representative for all CFS/ME populations in primary, secondary or tertiary care. Also this sample had a relatively high duration of illness and the extent to which these results can be generalised to a wider population of people with CFS/ME is therefore unknown. However, people who belong to the CFS/ME self-help organisations are diverse in age, the type of care they receive and in geographical location within Great Britain.

As this is, as far as we know, the first study to investigate the role of illness intrusiveness in people with CFS/ME, it is important that these findings are confirmed with different types of CFS/ME patients, that is, those in primary, secondary, or tertiary care. Also, although duration of illness did not appear to affect the variables of interest, the results need to be replicated on a group of CFS/ME patients who have had CFS/ME for a shorter length of time.

In summary, we suggest that the impairment and experience of CFS/ME is depressing not only because of the psychological impact but because of its effects on lifestyle and therefore quality of life; the current study has shown that in comparison with other illnesses which are accepted as medically significant chronic diseases (such as MS, ESRD and heart disease) CFS/ME is highly intrusive and alarmingly disabling. Johnson et al. (1996) suggest that depression is (partly at least) due to the lack of medical recognition of the illness and the uncertainty of prognosis. Recognition of this fact by the medical profession is extremely important to sufferers of CFS/ME (Lehman, Lehman, Hemphill, Mandel, \& Cooper, 2002).

The results show that there is neither a strong direct link between symptom severity and depression, nor between impairment and depression. There are indirect effects (via illness intrusiveness) for both impairment and symptom severity; both impairment and symptom severity have a stronger relationship to illness intrusiveness than they do to depression. Although this study shows the way in which symptom severity and impairments relate to depression, the model is far from complete. Research shows that there are various moderator variables such as age, income, stressful life events etc. which affect illness intrusiveness, which in turn affect outcome measures such as quality of life (Devins et al. 2006). Emotional distress, stressful events, perceived stigma and social support are likely to be moderator variables in CFS/ME. Work by Edworthy et al. (2003) showed that group psychotherapy reduced the intrusiveness of SLE and helped patients adapt to the illness. Educational and Management programmes based on the knowledge of the ways in which illness intrusiveness relates to symptoms and depression may be another psychosocial treatment arm which can be used alongside other intervention programmes.

It will be important for other researchers to add to the model to elucidate the ways in which important psychological, social and physical factors contribute to well-being in people with CFS/ME. Acknowledging the high level of intrusiveness inherent in CFS/ME by health professionals is likely in itself to lead to feelings of support and validity, which may help mitigate the adverse psychosocial concomitants of this illness.

\section{Acknowledgements}

The authors would like to thank the ME Association and Action for ME for allowing us to advertise for research volunteers in their publications. Thank you also to Professor Leslie $\mathrm{J}$ Findley who gave advice on one of the questionnaires used in the study. We would particularly like to express our thanks to Dr Charles Shepherd, Honorary Medical Advisor of the ME Association, who gave welcome advice and suggestions to us in the initial stages of this research. Our deepest thanks of course go to those women who agreed to participate in this study - their time and effort is greatly appreciated. 


\section{References}

Afari, N., \& Buchwald, D. (2003). Chronic fatigue syndrome: A review. American Journal of Psychiatry, 160, 221-236.

Baron, R. M., \& Kenny, D. A. (1986). The moderator-mediator variable distinction in social psychological research: Conceptual, strategic and statistical considerations. Journal of Personality and Social Psychology, 51, 1173-1183.

Buchwald, D., Pearlman, T., Umali, J., Schmailing, K., \& Katon, W. (1996). Functional status in patients with chronic fatigue syndrome, other fatiguing illnesses, and healthy individuals. The American Journal of Medicine, 101, 364-370.

CFS/ME Working Group (2002). A Report of the CFS/ME Working Group. Report to the Chief Medical Officer of an Independent Working Group. (Retrieved May 2007) Available at: http://www.dh.gov.uk

Cox, D. L., \& Findley, L. J. (1998). The management of chronic fatigue syndrome in an inpatient setting: Presentation of an approach and perceived outcome. British Journal of Occupational Therapy, 61, 405-409.

Dancey, C. P., Hutton-Young, S. A., Moye, S., \& Devins, G. M. (2002). Perceived stigma, illness intrusiveness and quality of life in men and women with irritable bowel syndrome. Psychology, Health \& Medicine, 7, 381-395.

Deale, A., Chalder, T., Marks, I., \& Wessely, S. (1997). Cognitive therapy for chronic fatigue syndrome: A randomised controlled trial. American Journal of Psychiatry, 154, 408-414. Delongis, A., Folkman, S., \& Lazarus, R. S. (1988). The impact of daily stress on health and mood: Psychological and social resources as mediators. Journal of Personality and Social Psychology, 54, 486-495.

Devanur, L. D., \& Kerr, J. R. (2006). Chronic fatigue syndrome. Journal of Clinical Virology, 37, 139-150.

Devins, G. M. (1994). Illness intrusiveness and the psychosocial impact of lifestyle disruptions in chronic life-threatening disease. Advances in Renal Replacement Therapy, 1, 251-263.

Devins, G. M., Bezjak, A., Mah, K., Loblaw, D. A., \& Gotowiec, A. P. (2006). Context moderates illness-induced lifestyle disruptions across life domains: A test of the illness intrusiveness theoretical framework in six common cancers. Psycho-oncology, 15, 221-233.

Devins, G. M., Dion, R., Pelletier, L. G., Shapiro, C. M., Abbey, S., Raiz, L. R., et al. (2001). Structure of lifestyle disruptions in chronic disease - A confirmatory factor analysis of the illness intrusiveness ratings scale. Medical Care, 39, 1097-1104.

Devins, G. M., Edworthy, S. M., Guthrie, N., \& Martin, L. (1992). Illness intrusiveness in rheumatoid arthritis: Differential impact on depressive symptoms over the adult lifespan. The Journal of Rheumatology, 19, 709-715.

Devins, G. M., Edworthy, S. M., Seland, T. P., Klein, G. M., Paul, L. C., \& Mandin, H. (1993b). Differences in illness intrusiveness across rheumatoid arthritis, end-stage renal disease and multiple sclerosis. Journal of Nervous and Mental Disease, 181, 377-381.

Devins, G. M., Edworthy, S. M., Seland, T. P., Klein, G. M., Paul, L. C., Mandin, H., et al. (1993a). Restless sleep, illness intrusiveness and depressive symptoms in three chronic illness conditions - Rheumatoid arthritis, end-stage renal disease and multiple sclerosis. Journal of Psychosomatic Research, 37, 163-170. 
Devins, G. M., Flanigan, M., Fleming, J. A. E., Morehouse, R., Mosocovitch, A., Plamondon, J., et al. (1995). Differential illness intrusiveness associated with sleep-promoting medications. European Psychiatry, 10, 153s-159s.

Devins, G. M., Mandin, H., Hons, R. B., Burgess, E. D., Klassen, J., Taub, K., et al. (1990). Illness intrusiveness and quality of life in end-stage renal disease: Comparison and stability across treatment modalities. Health Psychology, 9, 117-142.

Devins, G. M., Stam, H. J., \& Koopmans, J. P. (1994). Psychosocial impact of laryngectomy mediated by perceived stigma and illness intrusiveness. Canadian Journal of Psychiatry, 39, 608-616.

Devins, G. M., Styra, R., O'Connor, P., Gray, T., Seland, T. P., Klein, G. M., et al. (1996). Psychosocial impact of illness intrusiveness moderated by age in multiple sclerosis. Psychology, Health and Medicine, 1, 179-191.

Edworthy, S. M., Dobkin, P. L., Clarke, A. E., Da Costa, D., Dritsa, M., Fortin, P. R., et al. (2003). Group psychotherapy reduces illness intrusiveness in systemic lupus erythematosus. Journal of Rheumatology, 30, 1011-1016.

Fulcher, K. Y., \& White, P. D. (1997). Randomised controlled trial of graded exercise in patients with the chronic fatigue syndrome (1997). British Medical Journal, 314, 1647-1652.

Fukuda, K., Straus, S., Hickie, I., Sharpe, M. C., Dobbins, J. G., \& Komaroff, A. (1994). The chronic fatigue syndrome: A comprehensive approach to its definition and study. Annals of Internal Medicine, 121, 953-959.

Hardt, J., Buchwald, D., Wilks, D., Sharpe, M., Nix, A., \& Egle, U.T. (2001). Health-related quality of life in patients with chronic fatigue syndrome. An international study. Journal of Psychosomatic Research, 51, 431-434.

Heim, C., Wagner, D., Maloney, E., Papanicolaou, D. A., Solomon, L., James, J. F., et al. (2006). Early adverse experience and risk for chronic fatigue syndrome - Results from a population-based study. Archives of General Psychiatry, 63, 1258-1266.

Henningsen, P., Zimmermann, T., \& Sattel, H. (2003). Medically unexplained physical symptoms, anxiety and depression: A meta-analytic review. Psychosomatic Medicine, 65, 528-533.

Hotopf, M. H., \& Wessely, S. (1994). Viruses, neurosis and fatigue. Journal of Psychosomatic Research, 38, 499-514.

Iversen, A., \& Wessely, S. (2003). Chronic fatigue and depression. Current Opinion in Psychiatry, 16, 17-21.

Johnson, S. K., DeLuca, J., \& Natelson, B. H. (1996). Depression in fatiguing illness:

Comparing patients with chronic fatigue syndrome, multiple sclerosis and depression. Journal of Affective Disorders, 39, 21-30.

Keller, R. H., Lane, J. L., Klimas, N., Reiter, W. M., Fletcher, M. A., Vanriel, F., et al. (1994). Association between HLA Class-II antigens and the chronic fatigue immune dysfunction syndrome. Clinical Infectious Diseases, 18, S154-S156.

Lehman, A. M., Lehman, D. R., Hemphill, K. J., Mandel, D. R., \& Cooper, L. M. (2002). Illness experience, depression and anxiety in chronic fatigue syndrome. Journal of Psychosomatic Research, 52, 461-465.

Lloyd, A. R., Hickie, I., Brockman, A., Hickie, C., Wilson, A., Dwyer, J., \& Wakefield, D.

(1993). Immunologic and psychologic therapy for patients with chronic fatigue syndrome: A double-blind, placebo-controlled trial. American Journal of Medicine, 94,197-203. 
Looper, K. J., \& Kirmayer, L. J. (2004). Perceived stigma in functional somatic syndromes and comparable medical conditions. Journal of Psychosomatic Research, 57, 373-378.

Prins, J., Bleijenberg, G., Bazelmans, E., Elving, L., De Boo, T., Severens, J., et al. (2001). Cognitive behaviour therapy for chronic fatigue syndrome: A multicentre randomised controlled trial. The Lancet, 357, 841-847.

Powell, P., Bentall, R. P., Nye, F. J., \& Edwards, R. H. (2001). Randomized controlled trial of patient education to encourage graded exercise in chronic fatigue syndrome. British Medical Journal, 322, 387-390.

Radloff, L. S. (1977). The CES-D scale: A self-report depression scale for research in the general population. Applied Psychological Measurement, 1, 385-401.

Radloff, L. S. (1991). The use of the centre for epidemiologic studies in adolescents and young adults. Journal of Youth and Adolescence, 20, 149-166.

Rakib, A., White, P. D., Pinching, A. J., Hedge, B., Newbery, N., Fakhoury, W.K., et al. (2005). Subjective quality of life in patients with chronic fatigue syndrome. Quality of life research: An International Journal of Quality of Life Aspects of Treatment, Care \& Rehabilitation, 14, 11-19.

Ridsdale, L., Godfrey, E., Chalder, T., Seed, P., King, M., Wallace, P., et al. (2001). Chronic fatigue in general practice: Is counselling as good as cognitive behaviour therapy? A UK randomised trial. British Journal of General Practice, 51, 19-24.

Schweitzer, R., Kelly, B., Foran, A., Terry, D., \& Whiting, J. (1995). Quality of life in chronic fatigue syndrome. Social Science and Medicine, 41, 1367-1372.

Sharpe, M., Hawton, K., \& Simkin, S. (1996). Cognitive behaviour therapy for the chronic fatigue syndrome: A randomised controlled trial. British Medical Journal, 312, 22-26.

Sharpe, M., Hawton, K., Simkin, S., Surawy, C., Hackmann, A., Klimes, I., et al. (1996). Cognitive behaviour therapy for the chronic fatigue syndrome: A randomised controlled trial. British Medical Journal, 312, 22-26.

Shawaryn, M. A., Schiaffino, K. M., Larocca, N. G., \& Johnston, M. V. (2002). Determinants of health-related quality of life in multiple sclerosis: The role of illness intrusiveness. Multiple Sclerosis, 8, 310-319.

Shepherd, C., \& Chaudhuri, A. (2005). ME/CFS/PVFS: An exploration of the key clinical issues. The ME association.

Talbot, F., Nouwen, A., Gingras, J., Belanger, A., \& Audet, J. (1999). Relations of diabetes intrusiveness and personal control of symptoms of depression among adults with diabetes. Health Psychology, 18, 537-542.

Taillefer, S., Kirmayer, L. J., Robbins, J. M., \& Lasry, J. (2003). Correlates of illness worry in chronic fatigue syndrome. Journal of Psychosomatic Research, 54, 331-337.

Wessely, S., \& Powell, R. (1989). Fatigue syndromes: A comparison of chronic 'post-viral' fatigue with neuromuscular and affective disorder. Journal of Neurology, Neurosurgery and Psychiatry, 52, 940-948.

Wearden, A. J., Morriss, R. K., Mullis, R., Strickland, P. L., Pearson, D. J., Appleby, L., et al. (1998). Randomised, double-blind, placebo-controlled treatment trial of fluoxetine and graded exercise for chronic fatigue syndrome. British Journal of Psychiatry, 172, 485-492.

White, K., Lehman, D. R., Hemphill, K. J., Mandel, D. R., \& Lehman, A. M. (2006). 
Causal attributions, perceived control and psychological adjustment: A study of chronic fatigue syndrome. Journal of Applied Social Psychology, 36, 75-99.

Whiting, P., Bagnall, A., Sowden, A., Cornell, J. E., Mulrow, C. D., \& Ramfrez, G. (2001). Interventions for the treatment and management of chronic fatigue syndrome: A systematic review. Journal of American Medical Association, 286, 1360-1401.

White, C., \& Schweitzer, R. (2000). The role of personality in the development and perpetuation of chronic fatigue syndrome. Journal of Psychosomatic Research, 48, 515-524.

Wood, B., \& Wessely, S. (1999). Personality and social attitudes in chronic fatigue syndrome. Journal of Psychosomatic Research, 47, 385-397. 